Case Report

\title{
Uterine Fibroid Torsion during Pregnancy: A Case of Laparotomic Myomectomy at 18 Weeks' Gestation with Systematic Review of the Literature
}

\author{
Annachiara Basso, ${ }^{1}$ Mariana Rita Catalano, ${ }^{1}$ Giuseppe Loverro, ${ }^{1}$ \\ Serena Nocera, ${ }^{1}$ Edoardo Di Naro, ${ }^{1}$ Matteo Loverro, ${ }^{1}$ \\ Mariateresa Natrella, ${ }^{2}$ and Salvatore Andrea Mastrolia ${ }^{1}$ \\ ${ }^{1}$ Department of Obstetrics and Gynecology, Azienda Ospedaliera Universitaria Policlinico di Bari, School of Medicine, \\ Università degli Studi di Bari "Aldo Moro", Bari, Italy \\ ${ }^{2}$ School of Nursing, Azienda Ospedaliera Universitaria Policlinico di Bari, School of Medicine, \\ Università degli Studi di Bari "Aldo Moro", Bari, Italy
}

Correspondence should be addressed to Salvatore Andrea Mastrolia; mastroliasa@gmail.com

Received 15 January 2017; Revised 17 March 2017; Accepted 20 March 2017; Published 24 April 2017

Academic Editor: Maria Grazia Porpora

\begin{abstract}
Copyright (C) 2017 Annachiara Basso et al. This is an open access article distributed under the Creative Commons Attribution License, which permits unrestricted use, distribution, and reproduction in any medium, provided the original work is properly cited.

Uterine myomas are the most common benign growths affecting female reproductive system, occurring in $20-40 \%$ of women, whereas the incidence rate in pregnancy is estimated from 0.1 to $3.9 \%$. The lower incidence in pregnancy is due to the association with infertility and low pregnancy rates and implantation rates after in vitro fertilization treatment. Uterine myomas, usually, are asymptomatic during pregnancy. However, occasionally, pedunculated fibroids torsion or other superimposed complications may cause acute abdominal pain. There are many controversies in performing myomectomy during cesarean section because of the risk of hemorrhage. Nevertheless, the majority of indication arises before labor and delivery due to acute symptoms leading to a discussion regarding the need for intervention during pregnancy. Therefore, we present a case of successful multiple laparotomic myomectomy at $17+2$ weeks of gestational age and a systematic review of the literature in order to clarify the approach to this pathologic condition and its effect on pregnancy outcome.
\end{abstract}

\section{Introduction}

Uterine myomas are the most common benign growths affecting female reproductive system, occurring in $20-40 \%$ of women [1], whereas the incidence rate in pregnancy is estimated from 0.1 to $3.9 \%$. The lower incidence in pregnancy is due to the association with infertility and low pregnancy rates and implantation rates after in vitro fertilization treatment [2]. Uterine myomas, usually, are asymptomatic during pregnancy. However, occasionally, pedunculated fibroids torsion or other superimposed complications may cause acute abdominal pain. Urinary and gastroenteric symptoms may occur due to the rapid increase in size in reason of hyperestrogenic environment and, consequently, compression and displacement of surrounding organs. Additionally, fibroids predispose to pregnancy complications, including early miscarriage, antepartum bleeding, preterm labor, premature rupture of membranes, fetal malpresentations, labor dystocia, and postpartum hemorrhage.

Conservative management with anti-inflammatory therapy is considered a gold standard, and surgery is generally avoided during pregnancy because of the risks of hysterectomy secondary to severe hemorrhage, pregnancy injury, and pregnancy loss [3]. The main conditions that induce inevitably the surgical procedure are the torsion of pedunculated fibroids or rare cases of necrosis, resultant inflammatory peritoneal reaction, and, finally, if symptoms persist after 72 hours of pharmacological therapy [4-7]. Therefore, the diagnosis needs a particular attention for the appropriate management choice. Surgical removal fibroids in pregnancy can be performed by laparotomy or laparoscopy technique taking into account the volume and location of nodules $[1,8]$. 
Laparoscopy can be considered in selected cases such as small, subserous, pedunculated myomas.

There are many controversies in performing myomectomy during cesarean section because of the risk of hemorrhage [3]. Nevertheless, the majority of indication arises before labor and delivery due to acute symptoms leading to a discussion regarding the need for intervention during pregnancy.

Therefore, we present a case of successful multiple laparotomic myomectomy at $17+2$ weeks of gestational age and a systematic review of the literature in order to clarify the approach to this pathologic condition and its effect on pregnancy outcome.

\section{Case Report}

Uterine myomas are usually asymptomatic during pregnancy. However, pedunculated fibroids torsion may occasionally cause acute abdominal pain [1].

Most cases of laparotomic myomectomy described in literature have been performed during a cesarean section due to the risk of managing them surgically at low gestational age [2-4]. We present a case of a successful multiple laparotomic myomectomy during the second trimester of pregnancy.

A 36-year-old, morbidly obese primigravida presented at our emergency room at $17+0$ weeks of gestational age complaining of abdominal pain. At clinical examination, the uterus appeared to be of higher volume compared to the gestational age, the abdomen was painful but treatable, and the obstetrical examination was normal. The patient was then referred to US Unit of our Department for further evaluation. The sonographic assessment revealed the presence of three subserous uterine myomas located on anterior wall (maximum diameter: $13.2 \mathrm{~cm}$ ), the right wall (maximum diameter: $12.6 \mathrm{~cm}$ ), and the left wall (maximum diameter: $11.7 \mathrm{~cm}$ ) of the uterus, respectively. All myomas were vacuolated inside as for suspected necrosis. The scan also showed other multiple myomas less than $3 \mathrm{~cm}$ in size. Vital signs were monitored (blood pressure 140/90 $\mathrm{mmHg}$, maternal heart rate $124 \mathrm{bmp}$, SO2 94\%, apyretic). Amniotic fluid was normal and fetal well-being was preserved. Thus, the patient was admitted to the High-Risk-Pregnancy Unit. When collecting the medical history, the first trimester ultrasound scan, performed at 11 weeks' gestation, revealed the presence of the same lesions with a size of $10.8 \mathrm{~cm}, 10.2 \mathrm{~cm}$, and $6.14 \mathrm{~cm}$, respectively.

Laboratory studies demonstrated rising inflammatory markers (C-reactive protein: $354 \mathrm{mg} / \mathrm{L}$; WBC: $16.92 \times 10^{3} \mu \mathrm{L}$ ).

Due to the persistence of the symptoms, despite of two days of analgesic, antispastic, and antibiotic therapy, after multidisciplinary discussion, and a thorough counseling to inform the parents of the surgical and postoperative risks connected with uterine surgery during the gestation, the patient underwent surgery. Laparotomy approach by longitudinal skin incision, considering the volume and the position of the myomas, was performed under general anesthesia. Three huge bulky subserous pedunculated myomas were evidenced, the largest located at the uterine fundus, with a maximum diameter of $15 \mathrm{~cm}$ and a torsion of its pedicle (Figure 1). Furthermore, intra-abdominal adhesions were found within

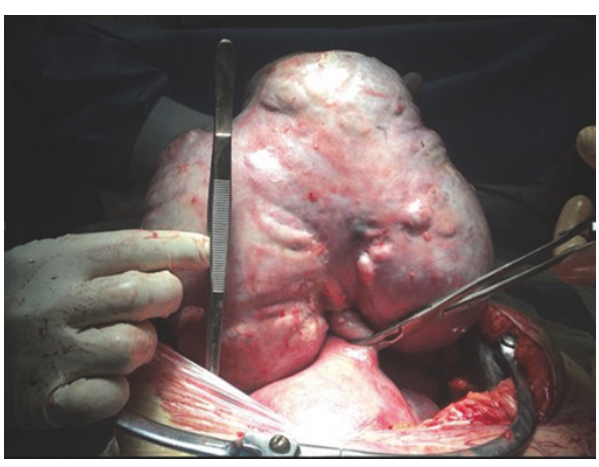

FIgURE 1: Myoma of the uterine fundus with evidence of torsion of its pedicle.

peritoneal cavity. Blunt dissection was undertaken to free the omentum and look for the appendix, which was normal. The three large myomas evidenced by ultrasound were removed and sent for pathologic examination. A pelvic drainage was left and removed 24 hours postoperatively. Pathology showed widespread phenomena of necrosis, especially in the myoma with torsion of its pedicle.

During the following nine days, the patient received antibiotics, low molecular heparin, and progesterone, and fetal heartbeat was checked daily. Considering the improvement in clinical condition, the patient was discharged with an indication to treatment with progesterone and low molecular heparin.

Three weeks later, at 21 weeks' gestation, the patient was admitted again due to abdominal pain. Obstetrical evaluation revealed cervical effacement and the transvaginal ultrasound scan showed a reduction of cervical length (18 mm), funneling, and sludge. An ultrasound scan was performed showing good fetal variables. Consequently, the therapy with progesterone was increased. The patient had a positive vaginal culture for Staphylococcus haemolyticus, urine culture was negative, and C-reactive protein resulted to be positive. Therefore, antibiotic therapy with macrolides was given, according to antibiogram result. A cervical cerclage was proposed to the patient, but she refused to undergo the procedure.

Hospitalization lasted for seven days; then the woman was discharged due to an improvement of her clinical condition. The patient underwent obstetric evaluation every two weeks until she presented in labor and delivered vaginally at 38 +1 weeks' gestation a healthy female newborn of $2940 \mathrm{~g}$, appropriate for gestational age according to national growth curves [9]. Apgar score was $9 / 10$ at $1^{\prime}$ and $5^{\prime}$ respectively.

\section{Data Source and Literature Search}

To identify potentially eligible studies, we searched PubMed, Scopus, and Cochrane Library (all from inception to 16 March 2017). No language restrictions were initially applied. We used a combination of key words and text words represented by "myomectomy," "myoma," and "pregnancy."

Two reviewers (Annachiara Basso and Mariana Rita Catalano) independently screened the titles and abstracts of 


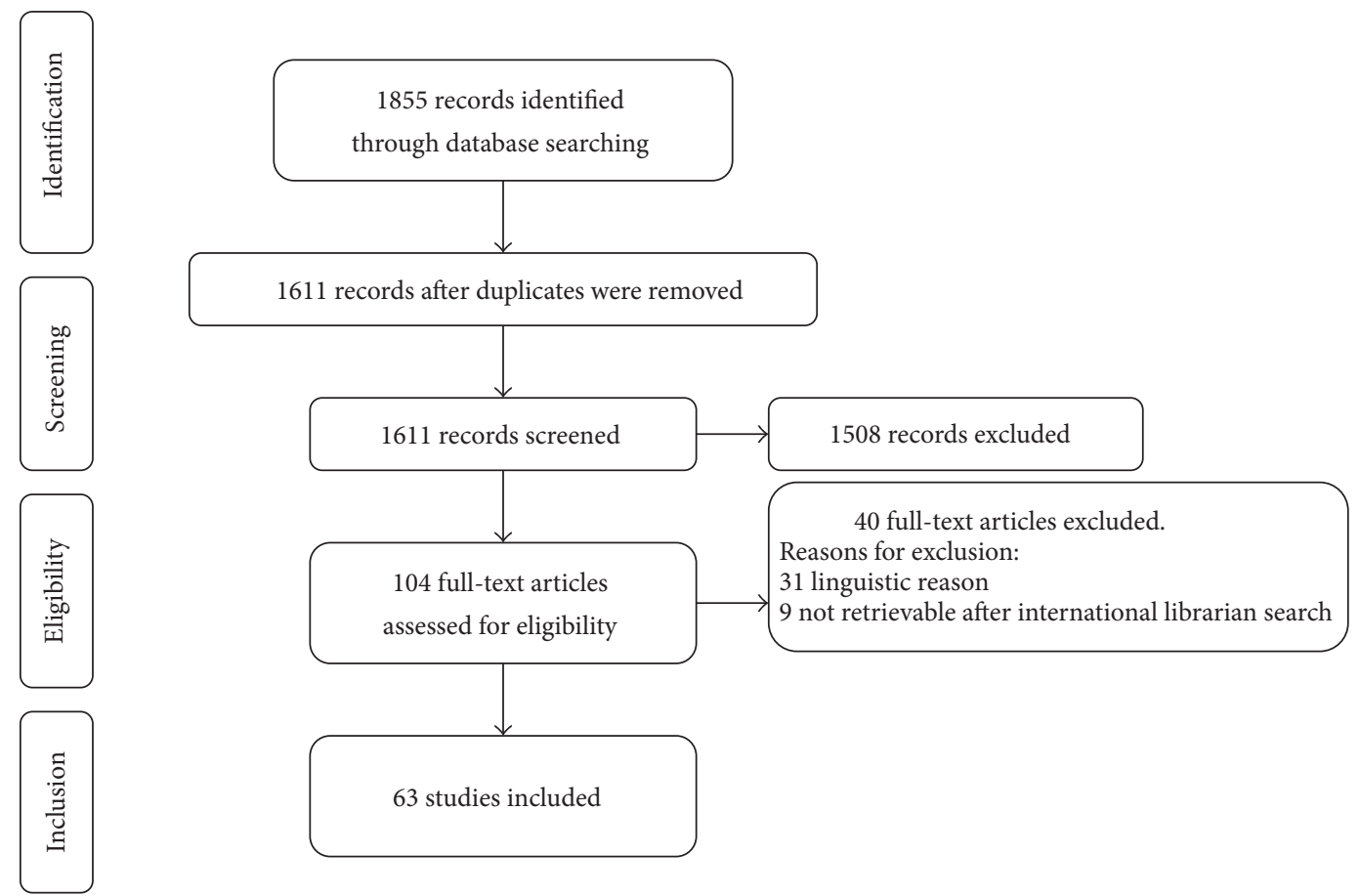

FIGURE 2: Study selection process.

records retrieved through database searches. Both reviewers recommended studies for the full-text review. The screen of full-text articles recommended by at least one reviewer was done independently by the same two reviewers and assessed for inclusion in the systematic review. Disagreements between reviewers were resolved by consensus. For all full-text manuscripts, reference lists were analyzed in order to find additional eligible studies.

\section{Results}

The electronic database search provided a total of 1855 results. After duplicate exclusion, there were 1611 citations left. Of these, 1508 were not relevant to the review based on title and abstract screening. 103 studies were considered for fulltext assessment, of which 40 were excluded for the following reasons: we could not translate 31 articles, while nine papers could not be retrieved even after international librarian search.

Overall, 63 [3-6, 10-67] articles were incorporated for further assessment. The study selection process is shown in Figure 2. The main characteristics of the selected studies are included in Table 1.

\section{Discussion}

Our review included 197 women undergoing myomectomy during pregnancy. The procedure was successful in 184 women, while in the remaining 13 cases a miscarriage or fetal demise happened after the myomectomy.
In 14 cases, a laparoscopic approach was chosen; in one case there was a vaginal surgery, while all the other cases for which the surgical information was available underwent laparotomy. These data confirm that the most used surgical intervention for myomas during pregnancy is the laparotomy route.

Maternal outcomes were favorable after myomectomy, with only two episodes of hemoperitoneum [33, 67], one uterine abscess [39], and only one woman requiring perioperative blood transfusion [61].

Moreover, the analysis of all reports was limited by two factors: (1) the heterogeneity of diagnostic information as well as descriptive data connected to operation and pathology examination which did not allow clear categorization of the pathology preoperatively and postoperatively and (2) the large amount of missing or unreported data.

\section{Conclusion}

Myomectomy is a feasible procedure if performed during pregnancy. Candidates need to be chosen carefully among those with symptomatic myomas, since abdominal surgery during pregnancy can be associated with an increased risk for the development of the great obstetrical syndromes, especially preterm labor and delivery.

\section{Disclosure}

This paper has been presented in part at the 19th National Congress of the Italian Society of Perinatal Medicine (Società 


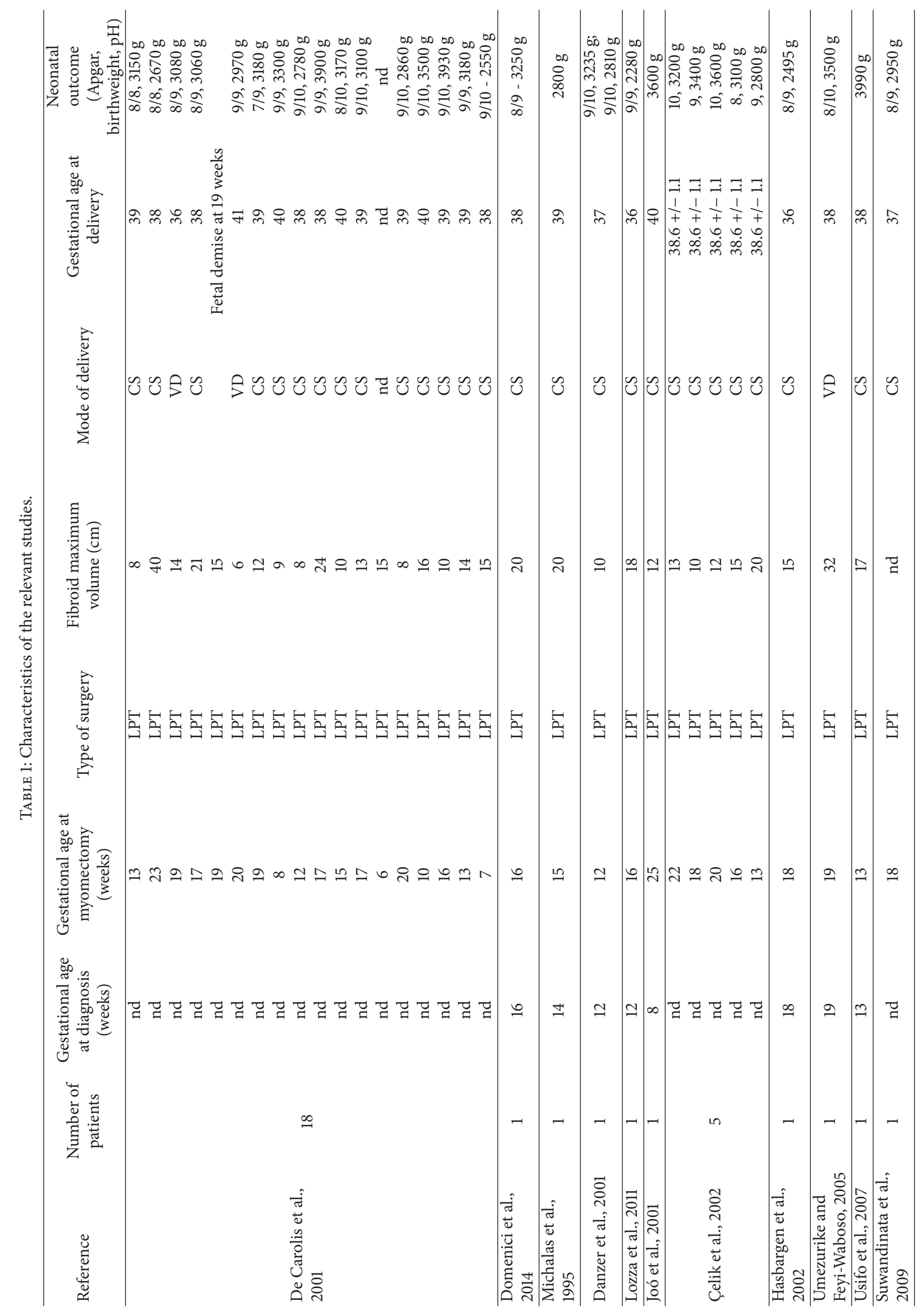




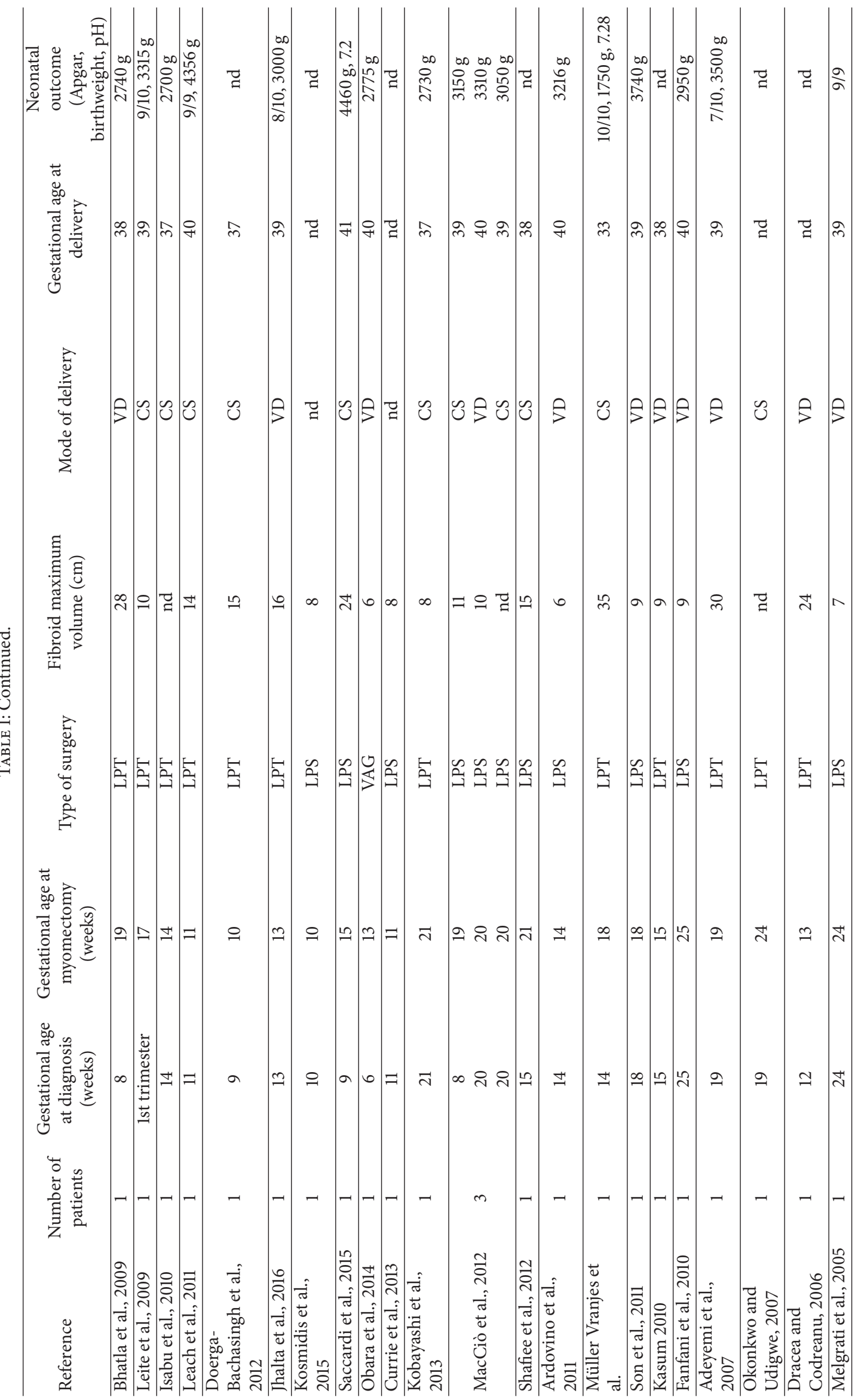




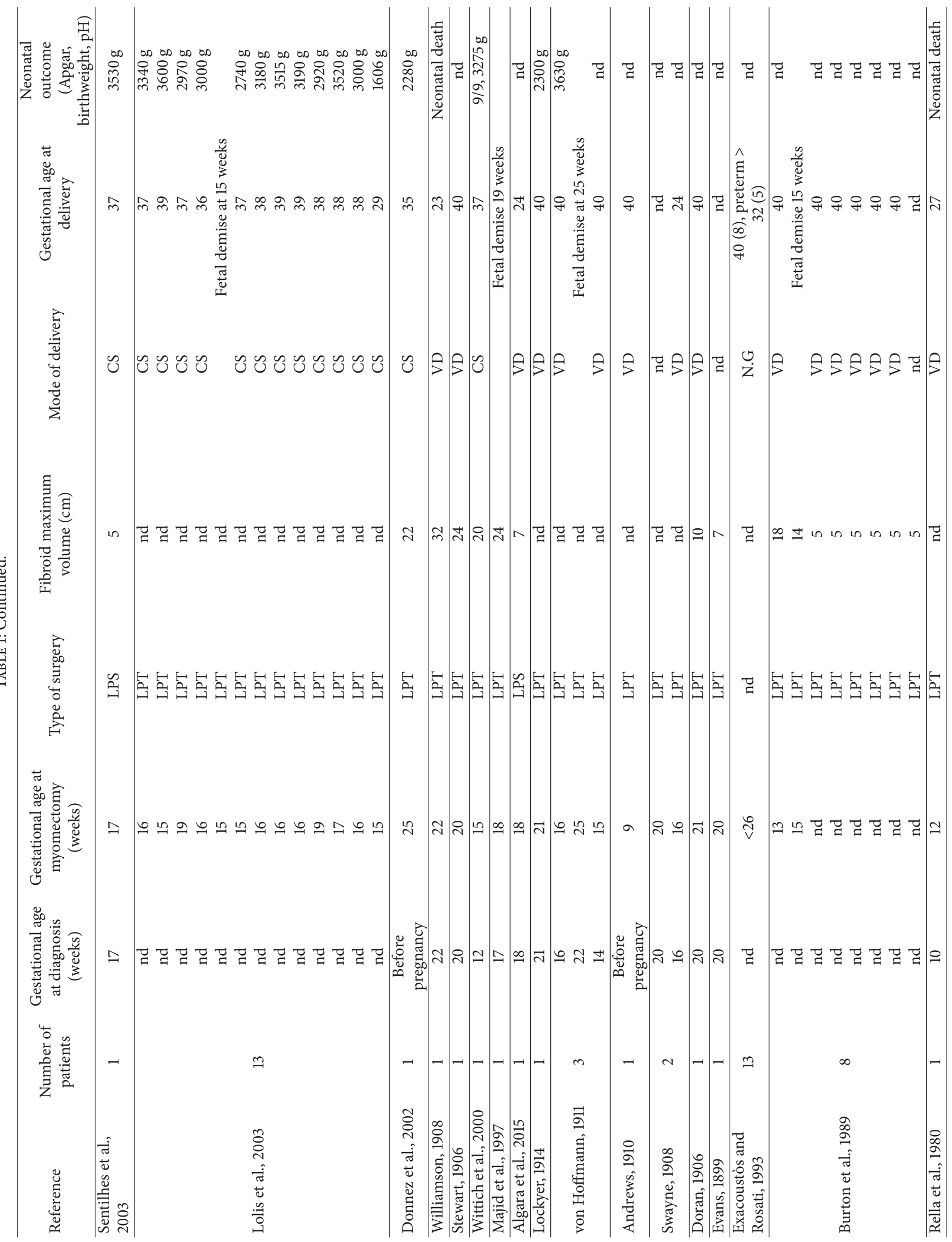




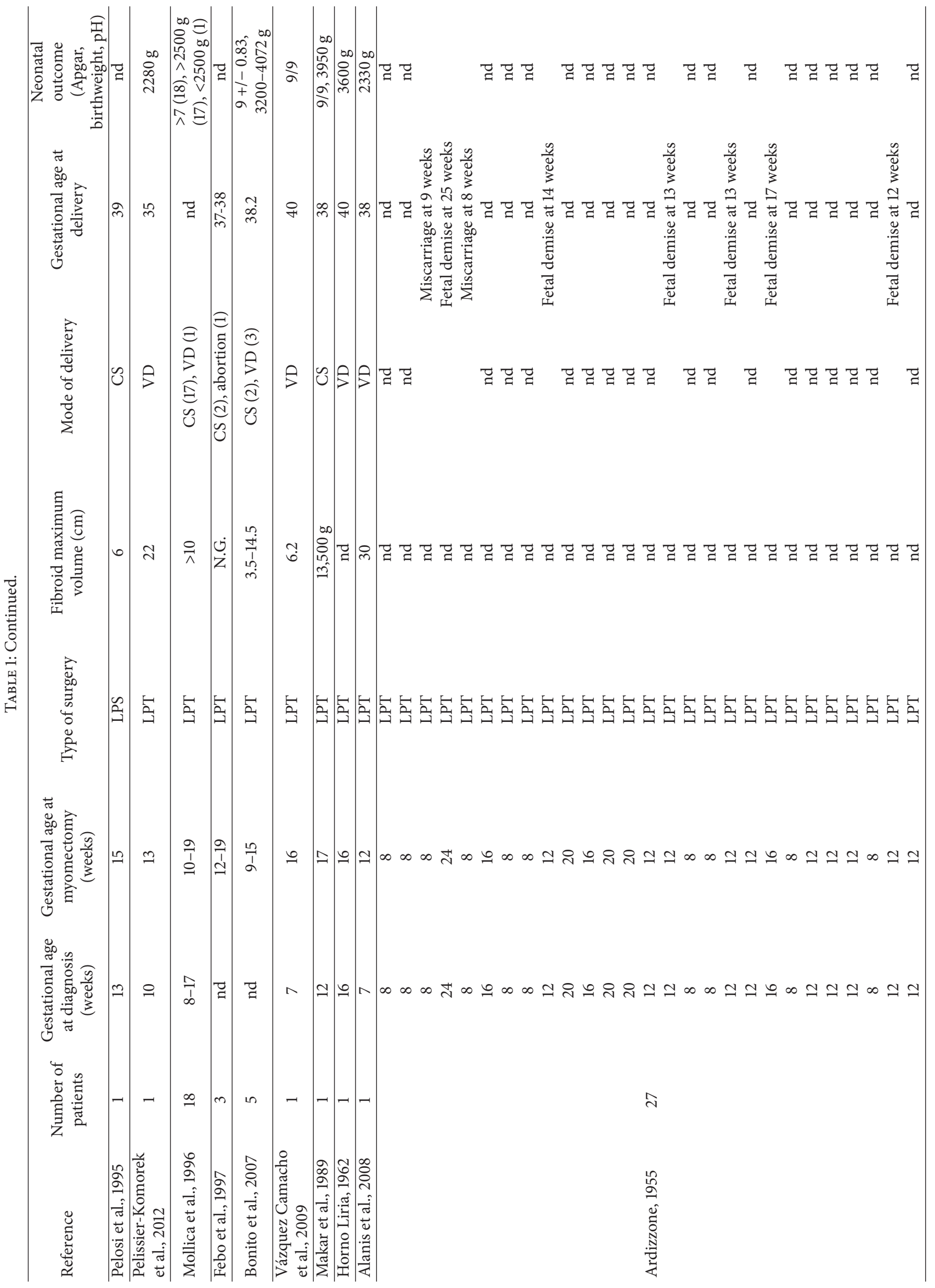




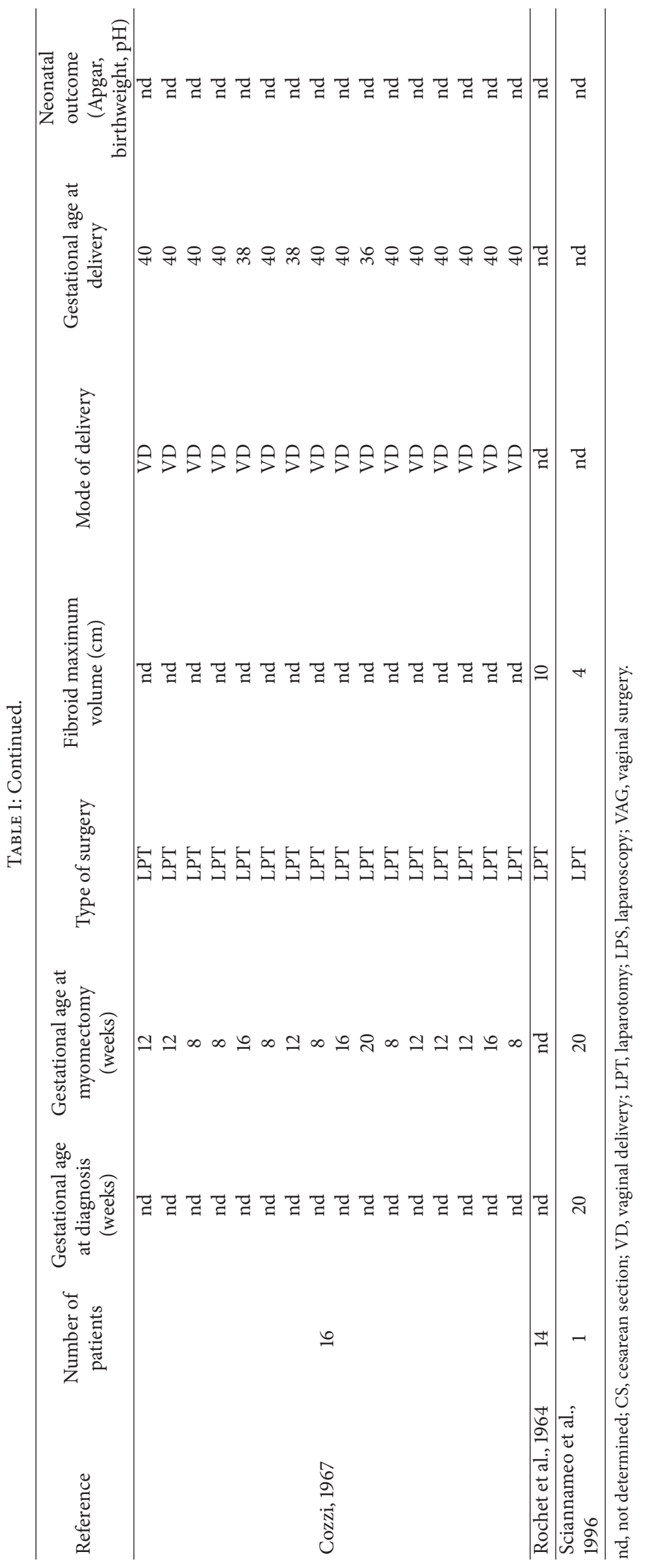


Italiana di Medicina Perinatale, SIMP), Naples (Italy), 19-21 January 2017.

\section{Conflicts of Interest}

The authors declare that there are no conflicts of interest.

\section{References}

[1] S. G. Vitale, A. Tropea, D. Rossetti, M. Carnelli, and A. Cianci, "Management of uterine leiomyomas in pregnancy: review of literature," Updates in Surgery, vol. 65, no. 3, pp. 179-182, 2013.

[2] S. K. Sunkara, M. Khairy, T. El-Toukhy, Y. Khalaf, and A. Coomarasamy, "The effect of intramural fibroids without uterine cavity involvement on the outcome of IVF treatment: a systematic review and meta-analysis," Human Reproduction, vol. 25, no. 2, pp. 418-429, 2010.

[3] V. Lozza, A. Pieralli, S. Corioni, M. Longinotti, and C. Penna, "Multiple laparotomic myomectomy during pregnancy: a case report," Archives of Gynecology and Obstetrics, vol. 284, no. 3, pp. 613-616, 2011.

[4] L. Domenici, V. Di Donato, M. L. Gasparri, F. Lecce, J. Caccetta, and P. B. Panici, "Laparotomic myomectomy in the 16th week of pregnancy: a case report," Case Reports in Obstetrics and Gynecology, 5 pages, 2014.

[5] D. E. Lolis, S. N. Kalantaridou, G. Makrydimas et al., "Successful myomectomy during pregnancy," Human Reproduction, vol. 18, no. 8, pp. 1699-1702, 2003.

[6] S. De Carolis, G. Fatigante, S. Ferrazzani et al., "Uterine myomectomy in pregnant women," Fetal Diagnosis and Therapy, vol. 16, no. 2, pp. 116-119, 2001.

[7] N. Bhatla, B. B. Dash, A. Kriplani, and N. Agarwal, "Myomectomy during pregnancy: a feasible option," Journal of Obstetrics and Gynaecology Research, vol. 35, no. 1, pp. 173-175, 2009.

[8] A. Cagnacci, D. Pirillo, S. Malmusi, S. Arangino, C. Alessandrini, and A. Volpe, "Early outcome of myomectomy by laparotomy, minilaparotomy and laparoscopically assisted minilaparotomy. A randomized prospective study," Human Reproduction, vol. 18, no. 12, pp. 2590-2594, 2003.

[9] F. Parazzini, S. Cipriani, G. Bulfoni et al., "Centiles of weight at term birth according to maternal nationality in a northern Italian region," Italian Journal of Gynaecology and Obstetrics, vol. 28, no. 2, pp. 52-56, 2016.

[10] S. P. Michalas, F. V. Oreopoulou, and J. S. Papageorgiou, "Myomectomy during pregnancy and caesarean section," Human Reproduction, vol. 10, no. 7, pp. 1869-1870, 1995.

[11] E. Danzer, W. Holzgreve, C. Batukan, P. Miny, S. Tercanli, and I. Hoesli, "Myomectomy during the first trimester associated with fetal limb anomalies and hydrocephalus in a twin pregnancy," Prenatal Diagnosis, vol. 21, no. 10, pp. 848-851, 2001.

[12] J. G. Joó, J. Inovay, M. Silhavy, and Z. Papp, "Successful enucleation of a necrotizing fibroid causing oligohydramnios and fetal postural deformity in the 25th week of gestation. A case report," Journal of Reproductive Medicine, vol. 46, no. 10, pp. 923-925, 2001.

[13] Ç. Çelik, A. Acar, N. Çiçek, K. Gezginc, and C. Akyürek, "Can myomectomy be performed during pregnancy?" Gynecologic and Obstetric Investigation, vol. 53, no. 2, pp. 79-83, 2002.
[14] U. Hasbargen, A. Strauss, M. Summerer-Moustaki et al., "Myomectomy as a pregnancy-preserving option in the carefully selected patient," Fetal Diagnosis and Therapy, vol. 17, no. 2, pp. 101-103, 2002.

[15] C. Umezurike and P. Feyi-Waboso, "Successful myomectomy during pregnancy: a case report," Reproductive Health, vol. 2, no. $1,2005$.

[16] F. Usifo, R. Macrae, R. Sharma, I. O. Opemuyi, and B. Onwuzurike, "Successful myomectomy in early second trimester of pregnancy," Journal of Obstetrics and Gynaecology, vol. 27, no. 2, pp. 196-197, 2007.

[17] F. S. Suwandinata, S. E. Gruessner, C. O. Omwandho, and H. R. Tinneberg, "Pregnancy-preserving myomectomy: preliminary report on a new surgical technique," European Journal of Contraception and Reproductive Health Care, vol. 13, no. 3, pp. 323-326, 2008, Erratum in: European Journal of Contraception and Reproductive Health Care, vol. 13, no. 4, article 438, 2008.

[18] G. K. Leite, H. A. Korkes, T. Viana Ade, A. Pitorri, G. Kenj, and N. Sass, "Myomectomy in the second trimester of pregnancy: case report," Revista Brasileira De Ginecologia E Obstetricia, vol. 32, no. 4, pp. 198-201, 2010.

[19] P. Isabu, J. Eigbefoh, F. Okogbo, S. Okunsanya, and R. Eifediyi, "Myomectomy during second trimester pregnancy: a case report," The Nigerian Postgraduate Medical Journal, vol. 17, no. 4, pp. 324-326, 2010.

[20] K. Leach, L. Khatain, and K. Tocce, "First trimester myomectomy as an alternative to termination of pregnancy in a woman with a symptomatic uterine leiomyoma: a case report," Journal of Medical Case Reports, vol. 5, article 571, 2011.

[21] S. Doerga-Bachasingh, V. Karsdorp, G. Yo, R. Van Der Weiden, and M. Van Hooff, "Successful myomectomy of a bleeding myoma in a twin pregnancy," JRSM Short Reports, vol. 3, no. 2, article 13, 2012.

[22] P. Jhalta, S. G. Negi, and V. Sharma, "Successful myomectomy in early pregnancy for a large asymptomatic uterine myoma: case report," Pan African Medical Journal, vol. 13, no. 24, article 228, Article ID 228, 2016.

[23] C. Kosmidis, G. Pantos, C. Efthimiadis, I. Gkoutziomitrou, E. Georgakoudi, and G. Anthimidis, "Laparoscopic excision of a pedunculated uterine leiomyoma in torsion as a cause of acute abdomen at 10 weeks of pregnancy," American Journal of Case Reports, vol. 16, pp. 505-508, 2015.

[24] C. Saccardi, S. Visentin, M. Noventa, E. Cosmi, P. Litta, and S. Gizzo, "Uncertainties about laparoscopic myomectomy during pregnancy: a lack of evidence or an inherited misconception? A critical literature review starting from a peculiar case," Minimally Invasive Therapy and Allied Technologies, vol. 24, no. 4, pp. 189-194, 2015.

[25] M. Obara, Y. Hatakeyama, and Y. Shimizu, "Vaginal myomectomy for semipedunculated cervical myoma during pregnancy," American Journal of Perinatology Reports, vol. 4, no. 1, pp. 37-40, 2014.

[26] A. Currie, E. Bradley, M. McEwen, N. Al-Shabibi, and P. D. Willson, "Laparoscopic approach to fibroid torsion presenting as an acute abdomen in pregnancy," Journal of the Society of Laparoendoscopic Surgeons, vol. 17, no. 4, pp. 665-667, 2013.

[27] F. Kobayashi, E. Kondoh, J. Hamanishi, Y. Kawamura, K. Tatsumi, and I. Konishi, "Pyomayoma during pregnancy: a case report and review of the literature," Journal of Obstetrics and Gynaecology Research, vol. 39, no. 1, pp. 383-389, 2013.

[28] A. MacCiò, C. Madeddu, P. Kotsonis et al., "Three cases of laparoscopic myomectomy performed during pregnancy for 
pedunculated uterine myomas," Archives of Gynecology and Obstetrics, vol. 286, no. 5, pp. 1209-1214, 2012.

[29] M. Shafiee, M. Nor Azlin, and D. Arifuddin, "A successful antenatal myomectomy," Malaysian Family Physician, vol. 31, no. 7(2-3), pp. 42-45, 2012.

[30] M. Ardovino, I. Ardovino, M. A. Castaldi, A. Monteverde, N. Colacurci, and L. Cobellis, "Laparoscopic myomectomy of a subserous pedunculated fibroid at 14 weeks of pregnancy: a case report," Journal of Medical Case Reports, vol. 5, article 545, 2011.

[31] A. Müller Vranjes, S. Sijanović, D. Vidosavljević, Z. Kasac, and K. Abicic Zuljević, "Surgical treatment of large smooth muscle tumor of uncertain malignant potential during pregnancy," Medicinski Glasnik Journal, vol. 8, no. 2, pp. 290-292, 2011.

[32] C. E. Son, J. S. Choi, J. H. Lee, S. W. Jeon, J. W. Bae, and S. S. Seo, "A case of laparoscopic myomectomy performed during pregnancy for subserosal uterine myoma," Journal of Obstetrics and Gynaecology, vol. 31, no. 2, pp. 180-181, 2011.

[33] M. Kasum, "Hemoperitoneum caused by a bleeding myoma in pregnancy," Acta Clinica Croatica, vol. 49, no. 2, pp. 197-200, 2010.

[34] F. Fanfani, C. Rossitto, A. Fagotti, P. Rosati, V. Gallotta, and G. Scambia, "Laparoscopic myomectomy at 25 weeks of pregnancy: case report," Journal of Minimally Invasive Gynecology, vol. 17, no. 1, pp. 91-93, 2010.

[35] A. S. Adeyemi, S. E. Akinola, and A. I. Isawumi, "Antepartum myomectomy with a live term delivery—a case report," Nigerian Journal of Clinical Practice, vol. 10, no. 4, pp. 346-348, 2007.

[36] J. E. N. Okonkwo and G. O. Udigwe, "Myomectomy in pregnancy," Journal of Obstetrics and Gynaecology, vol. 27, no. 6, pp. 628-630, 2007.

[37] L. Dracea and D. Codreanu, "Vaginal birth after extensive myomectomy during pregnancy in a 39-year-old nulliparous woman," Journal of Obstetrics and Gynaecology, vol. 26, no. 4, pp. 374-375, 2006.

[38] L. Melgrati, A. Damiani, G. Franzoni, M. Marziali, and F. Sesti, "Isobaric (gasless) laparoscopic myomectomy during pregnancy," Journal of Minimally Invasive Gynecology, vol. 12, no. 4, pp. 379-381, 2005.

[39] L. Sentilhes, F. Sergent, E. Verspyck, A. Gravier, H. Roman, and L. Marpeau, "Laparoscopic myomectomy during pregnancy resulting in septic necrosis of the myometrium," BJOG: An International Journal of Obstetrics and Gynaecology, vol. 110, no. 9, pp. 876-878, 2003.

[40] J. Donnez, C. Pirard, M. Smets, R. Polet, C. Feger, and J. Squifflet, "Unusual growth of a myoma during pregnancy," Fertility and Sterility, vol. 78, no. 3, pp. 632-633, 2002.

[41] H. Williamson, "Enucleation during the seventh lunar month of pregnancy of a uterine fibro-myoma," Proceedings of the Royal Society of Medicine, vol. 1, pp. 73-78, 1908.

[42] J. Stewart, "Enucleation of fibro-myoma of uterus during pregnancy," British Medical Journal, vol. 1, no. 2358, pp. 548$549,1906$.

[43] A. C. Wittich, E. R. Salminen, M. K. Yancey, and G. R. Markenson, "Myomectomy during early pregnancy," Military Medicine, vol. 165, no. 2, pp. 162-164, 2000.

[44] M. Majid, G. Q. Khan, and L. M. Wei, "Inevitable myomectomy in pregnancy," Journal of Obstetrics and Gynaecology, vol. 17, no. 4, pp. 377-378, 1997.

[45] A. C. Algara, A. G. Rodríguez, A. C. Vázquez et al., "Laparoscopic approach for fibroid removal at 18 weeks of pregnancy," Surgical Technology International, vol. 27, pp. 195-197, 2015.
[46] C. Lockyer, "Multiple myomectomy in the sixth month of pregnancy; labour at term," Proceedings of the Royal Society of Medicine, vol. 7, pp. 221-225, 1914.

[47] C. A. von Hoffmann, "Abdominal myomectomy during pregnancy," California State Journal of Medicine, vol. 9, no. 5, pp. 197200, 1911.

[48] H. R. Andrews, "Myomectomy during pregnancy," Proceedings of the Royal Society of Medicine, vol. 3, pp. 164-166, 1910.

[49] WC. Swayne, "Abdominal myomectomy during pregnancy," Proceedings of the Royal Society of Medicine, vol. 1, pp. 129-132, 1908.

[50] A. Doran, "Myomectomy during pregnancy and labour at term in an elderly primipara: with notes on similar cases," British Medical Journal, vol. 2, no. 2395, pp. 1446-1447, 1906.

[51] H. M. Evans, "A case of myomectomy for subperitoneal myoma complicating pregnancy," British Medical Journal, vol. 2, no. 2033, p. 1673, 1899.

[52] C. Exacoustòs and P. Rosati, "Ultrasound diagnosis of uterine myomas and complications in pregnancy," Obstetrics and Gynecology, vol. 82, no. 1, pp. 97-101, 1993.

[53] C. A. Burton, D. A. Grimes, and C. M. March, "Surgical management of leiomyomata during pregnancy," Obstetrics and Gynecology, vol. 74, no. 5, pp. 707-709, 1989.

[54] R. Rella, E. Bonfadini Bossi, and D. Fagnani, "Myomectomy in pregnancy. Description of an interesting clinical case," Minerva Ginecologica, vol. 32, no. 4, pp. 267-269, 1980.

[55] M. A. Pelosi, M. A. Pelosi III, and S. Giblin, "Laparoscopic removal of a 1500-g symptomatic myoma during the second trimester of pregnancy," American Association of Gynecologic Laparoscopists, vol. 2, no. 4, pp. 457-462, 1995.

[56] A. Pelissier-Komorek, J. Hamm, S. Bonneau, E. Derniaux, C. Hoeffel-Fornes, and O. Graesslin, "Myoma and pregnancy: when medical treatment is not sufficient," Journal de Gynecologie Obstetrique et Biologie de la Reproduction, vol. 41, no. 3, pp. 307-310, 2012.

[57] G. Mollica, L. Pittini, E. Minganti, G. Perri, and F. Pansini, "Elective uterine myomectomy in pregnant women," Clinical and Experimental Obstetrics and Gynecology, vol. 23, no. 3, pp. 168-172, 1996.

[58] G. Febo, M. Tessarolo, L. Leo, S. Arduino, T. Wierdis, and L. Lanza, "Surgical management of leiomyomata in pregnancy," Clinical and Experimental Obstetrics and Gynecology, vol. 24, no. 2, pp. 76-78, 1997.

[59] M. Bonito, L. Gulemì, R. Basili, and D. Roselli, "Myomectomy during the first and second trimester of pregnancy," Clinical and Experimental Obstetrics and Gynecology, vol. 34, no. 3, pp. 149150, 2007.

[60] E. E. Vázquez Camacho, E. Cabrera Carranco, and R. G. Sánchez Herrera, "Pedunculated twisted myoma and pregnancy. Case report," Ginecologia y Obstetricia de Mexico, vol. 77, no. 9, pp. 441-444, 2009.

[61] A. P. Makar, E. A. Schatteman, I. B. Vergote, and E. Desmedt, "Myomectomy during pregnancy: uncommon case report," Acta Chirurgica Belgica, vol. 89, no. 4, pp. 212-214, 1989.

[62] R. Horno Liria, "Myomectomy and pregnancy," Rev Esp Obstet Ginecol, vol. 19, pp. 214-218, 1962.

[63] M. C. Alanis, A. Mitra, and N. Koklanaris, "Preoperative magnetic resonance imaging and antepartum myomectomy of a giant pedunculated leiomyoma," Obstetrics and Gynecology, vol. 111, no. 2, part 2, pp. 577-579, 2008. 
[64] G. Ardizzone, "Clinical and statistical considerations of 27 cases of myomectomy in pregnancy," Rivista di Ostetricia e Ginecologia, vol. 10, no. 12, pp. 848-860, 1955.

[65] M. Cozzi, "Myomectomy in pregnancy," Quaderni di Clinica Ostetrica e Ginecologica, vol. 22, no. 3, pp. 171-180, 1967.

[66] Y. Rochet, M. Cognat, D. Dargent, and E. Pollosson, "On myomectomy during pregnance (apropos of 14 observations)," Bulletin de la Fèdèration des Sociètès de Gynècologie et Dòbstètrique de Langue Francaise, vol. 16, pp. 462-463, 1964.

[67] F. Sciannameo, G. Madami, C. Madami et al., "Torsion of uterine fibroma associated with inguinal incarcerated hernia in pregnancy. Case report," Minerva Ginecologica, vol. 48, no. 11, pp. 501-504, 1996. 


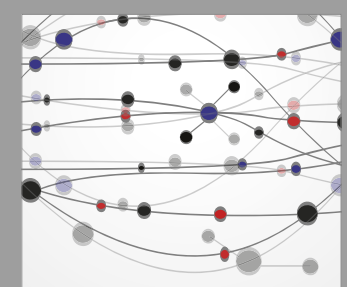

The Scientific World Journal
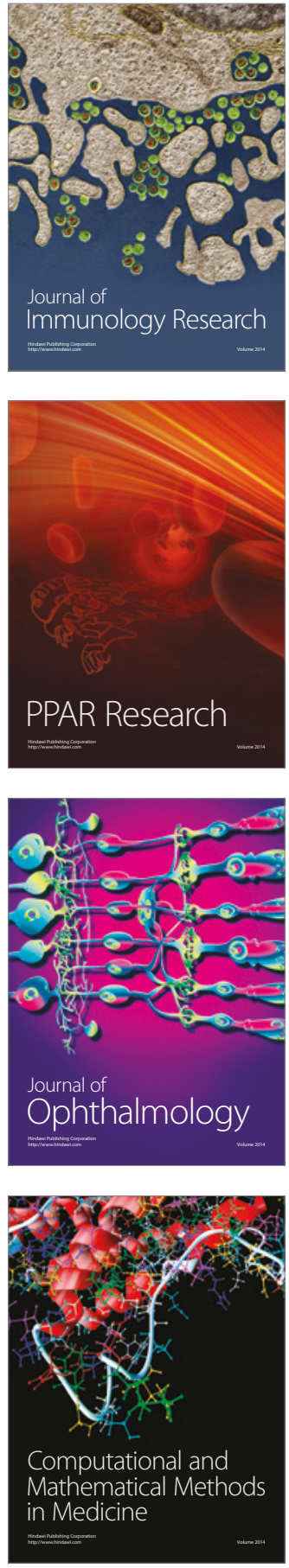

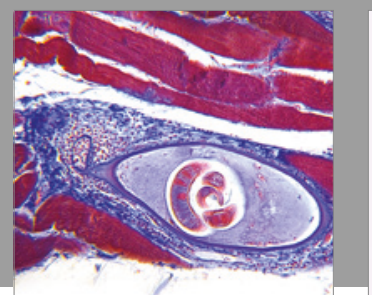

Gastroenterology Research and Practice
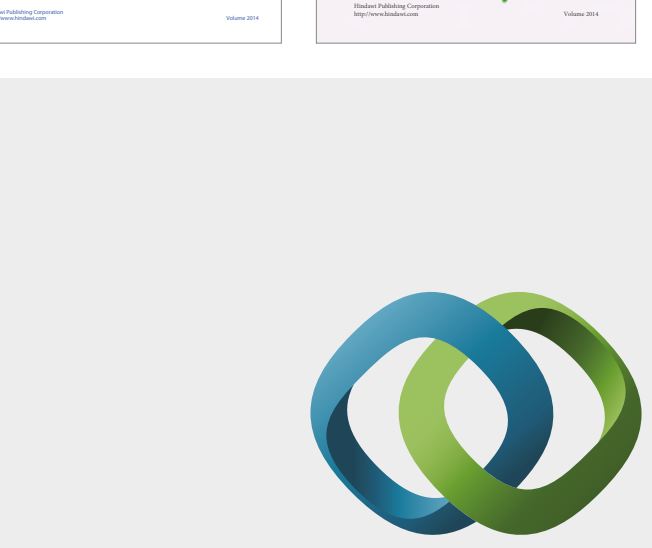

\section{Hindawi}

Submit your manuscripts at

https://www.hindawi.com
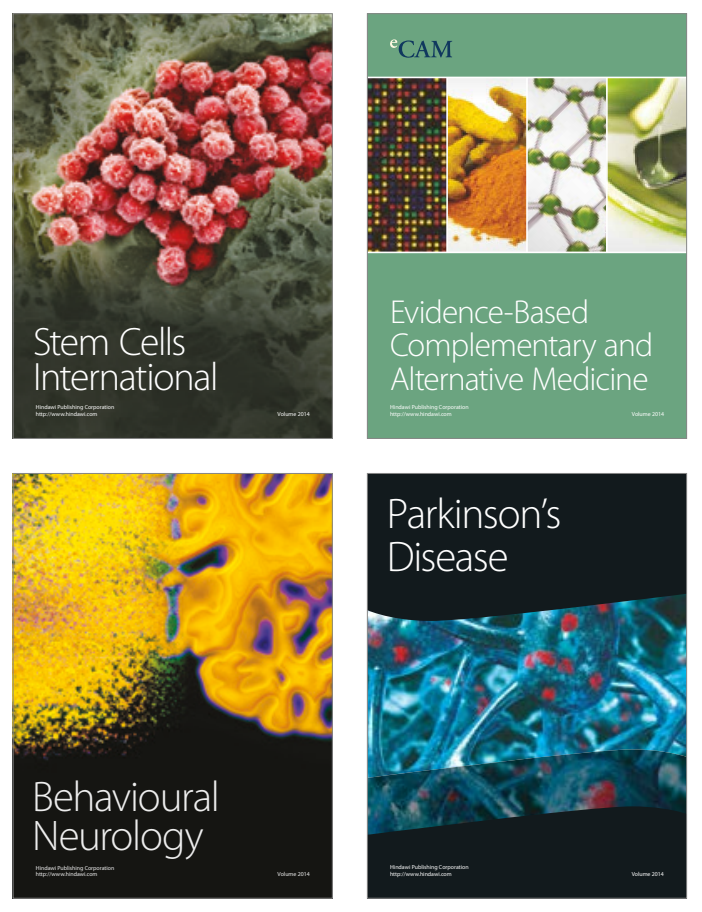
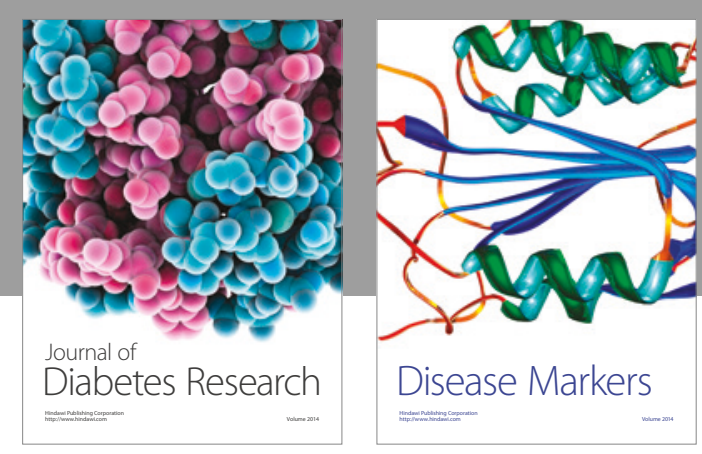

Disease Markers
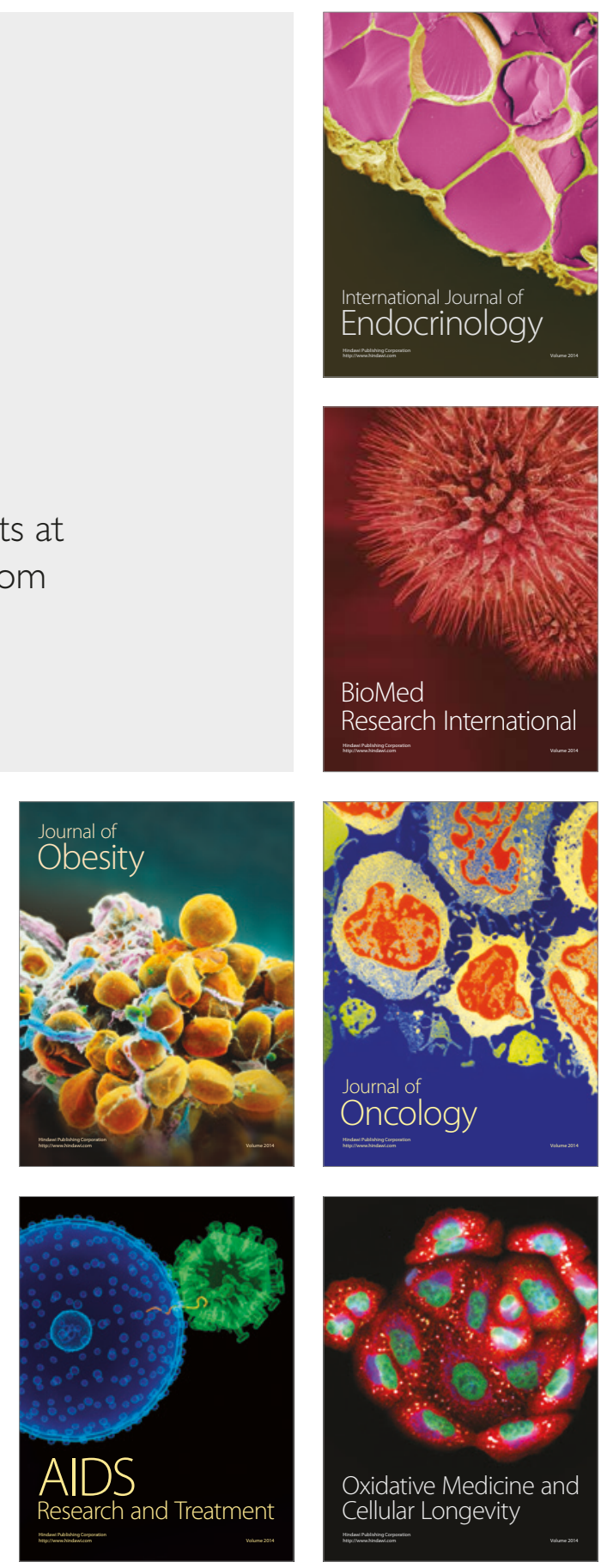